\title{
MCP-1-induced ERK/GSK-3ß/Snail signaling facilitates the epithelial-mesenchymal transition and promotes the migration of MCF-7 human breast carcinoma cells
}

\begin{abstract}
Shun $\mathrm{Li}^{1,3}$, Juan $\mathrm{Lu}^{1,3}$, Yu Chen ${ }^{1}$, Niya Xiong ${ }^{1}$, Li Li ${ }^{1}$, Jing Zhang ${ }^{1}$, Hong Yang ${ }^{1,2}$, Chunhui Wu ${ }^{1,2}$, Hongjuan Zeng ${ }^{1,2}$ and Yiyao Liu ${ }^{1,2}$

Monocyte chemoattractant protein-1 (MCP-1) is a chemotactic cytokine that can bind to its receptor cysteine-cysteine chemokine receptor 2 (CCR2) and plays an important role in breast cancer cell metastasis. However, the molecular mechanisms underlying MCP-1-induced alterations in cellular functions during tumor progression are poorly understood. Here, we showed that MCP-1 stimulated the epithelial-mesenchymal transition (EMT) and induced the tumorigenesis of breast cancer cells by downregulating E-cadherin, upregulating vimentin and fibronectin, activating matrix metallopeptidase-2 (MMP-2), and promoting migration and invasion. Moreover, MCP-1 treatment reduced glycogen

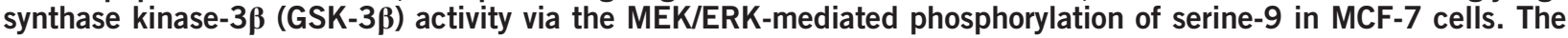
inhibition of MEK/ERK by U0126 attenuated the MCP-1-induced phosphorylation of GSK-3 $\beta$ and decreased the expression of Snail, an EMT-related transcription factor, leading to the inhibition of MCF-7 cell migration and invasion. Inactivation of GSK-3 $\beta$ by LiCl (lithium chloride) treatment notably increased MMP-2 activity, vascular endothelial growth factor expression and EMT of MCF-7 cells. These findings revealed that MCP-1-induced EMT and migration are mediated by the ERK/GSK-3 $\beta /$ Snail pathway, and identified a potential novel target for therapeutic intervention in breast cancer.
\end{abstract} Cellular \& Molecular Immunology (2017) 14, 621-630; doi:10.1038/cmi.2015.106; published online 21 March 2016

Keywords: EMT; ERK/GSK-3ß/Snail signaling; MCF-7; migration

\section{INTRODUCTION}

Monocyte chemoattractant protein-1 (MCP-1/CCL2) belongs to the cysteine-cysteine chemokine family ${ }^{1}$ and has been shown to play a critical role in modulating inflammation, ${ }^{1,2}$ regulating monocyte/macrophage trafficking during wound healing, ${ }^{3}$ infections, ${ }^{4}$ autoimmune diseases, ${ }^{5}$ and cancer. ${ }^{6,7}$ Chemokines and their receptors are involved in a wide range of normal physiological and pathological activities that impact cancer. ${ }^{7-10}$ Therefore, it is possible that they may have important effects on the regulation of carcinoma progression. Increased macrophage infiltration and macrophage-regulated angiogenesis associated with increased MCP-1 and vascular endothelial growth factor (VEGF) levels have been observed in breast cancer cells. ${ }^{11}$ In addition, both MCP-1 and VEGF expression levels have been positively correlated with tumor-associated macrophage infiltration, angiogenesis and poor prognosis in breast carcinoma patients. ${ }^{12}$ Interactions between tumor cells and macrophages increased MCP-1 expression and macrophage chemotactic activity, and an MCP-1 neutralizing antibody was able to reduce macrophage infiltration, angiogenesis and tumor growth in nude mice harboring human breast tumor xenografts. ${ }^{6}$

The epithelial-mesenchymal transition (EMT) is a complex process involved in tumor invasion and metastasis that is regulated by a variety of factors. There are reports that MCP-1 was involved in the EMT of peritoneal mesothelial cells, ${ }^{13}$ head and neck squamous cell carcinomas ${ }^{7,10}$ and early mammary carcinomas. Therefore, we speculate that MCP-1 may be a modulator of breast cancer cell EMT. EMT is a highly regulated process that is characterized by the loss of epithelial cell polarity and cell-cell adhesion and the acquisition of migratory and invasive properties. During this transition, cells lose expression of epithelial makers such as E-cadherin and acquire expression of mesenchymal proteins, including vimentin and fibronectin. At the molecular level, members of the basic helix-loop-helix family such as Snail can reduce E-cadherin gene expression through transcriptional suppression. Together with Snail, GSK-3 $\beta$ functions as a

\footnotetext{
${ }^{1}$ Department of Biophysics, School of Life Science and Technology, University of Electronic Science and Technology of China, Chengdu 610054, Sichuan, China and ${ }^{2}$ Center for Information in Biomedicine, University of Electronic Science and Technology of China, Chengdu 610054, Sichuan, China Correspondence: Professor Y Liu, PhD Department of Biophysics, School of Life Science and Technology, University of Electronic Science and Technology of China, Chengdu 610054, Sichuan, China.

E-mail: (liuyiyao@uestc.edu.cn or liuyiyao@hotmail.com)

${ }^{3}$ These authors contributed equally to this work.

Received: 14 October 2015; Revised: 28 November 2015; Accepted: 29 November 2015
} 
molecular switch for a number of signaling pathways that facilitate EMT. GSK-3 $\beta$ was initially identified as a key protein kinase involved in glycogen metabolism but is now known to modulate various biological events, including cellular proliferation, ${ }^{14}$ differentiation, ${ }^{15}$ migration, ${ }^{16}$ glucose regulation ${ }^{17}$ and apoptosis. ${ }^{18}$ GSK- $3 \beta$ is highly activated in carcinomas and is known to inhibit tumor migration and invasion and to maintain the epithelial morphology of tumor cells, as GSK-3 $\beta$ inhibition led to the acquisition of the mesenchymal phenotype. ${ }^{19}$ New evidence indicates that GSK-3 $\beta$ is able to maintain the epithelial phenotype by binding to transcription factors such as Snail ${ }^{20}$ and Slug ${ }^{21}$ to facilitate their ubiquitylation and degradation. In addition, the activation of GSK-3 $\beta$ can be potently regulated by MAPK (mitogen-activated protein kinase)-dependent phosphorylation. ${ }^{22}$ Devipriya et al. found that radiation could induce the MEK/ERKmediated inactivation of GSK-3 $\beta$, which led to the activation of Snail and EMT in lung carcinoma epithelial cells. ${ }^{23}$

Here, our study showed that MCP-1 could induce mesenchymal-like morphological changes in MCF-7 cells. We further explored the molecular mechanisms of MCP-1-driven EMT by evaluating the effects of MCP-1 on the migration and invasion of MCF-7 cells in vitro and on downstream signal transduction pathways. We found that MCP-1 promoted GSK-3 $\beta$ phosphorylation, upregulated the expression of the zinc finger transcription factor Snail, and increased the migration and invasion of MCF-7 cells via post-transcriptional mechanisms. Our data demonstrated that the MCP-1-induced EMT of MCF-7 cells was mediated by the ERK/GSK-3 $\beta /$ Snail signaling pathway.

\section{MATERIALS AND METHODS}

\section{Cell culture and treatment}

The MCF-7 cell line was obtained from the American Type Culture Collection (Manassas, VA, USA). MCF-7 cells were cultured in Roswell Park Memorial Institute 1640 (Gibco, Grand Island, NY, USA) supplemented with $10 \%$ fetal bovine serum (FBS; Gibco) and 1\% antibiotic-antimycotic reagent (Gibco) at $37^{\circ} \mathrm{C}$ in a humidified atmosphere of $5 \% \mathrm{CO}_{2}$ and $95 \%$ air. After culture in 12- or 24-well plates overnight, the cells were incubated for a period of time as indicated with one of the following treatments: $50 \mathrm{ng} / \mathrm{ml}$ of MCP-1 (PeproTech, Rocky Hill, CT, USA); $20 \mu \mathrm{M}$ of the CCR2 receptor antagonist RS102895 (Santa Cruz Biotech, Santa Cruz, CA, USA); $30 \mu \mathrm{M}$ of the MEK1/2 inhibitor U0126 (Sigma, Carlsbad, CA, USA); $40 \mu \mathrm{M}$ of the GSK-3 $\beta$ inhibitor lithium chloride (LiCl; Sigma); or $10 \mu \mathrm{M}$ of the PI3K inhibitor LY294002 (Sigma). The cell numbers were counted with a hemocytometer.

\section{Wound healing assay}

Using a previously described method, ${ }^{24} 1.5 \times 10^{5}$ MCF-7 cells were seeded into 24-well plates. After the cells were pretreated with RS102895 for $1 \mathrm{~h}$, wounds were generated by scratching with a pipette tip. The culture medium was removed by aspiration, displaced cells were removed with phosphate buffered saline (PBS), and MCP-1 (50 ng/ml) was added to the medium. Photos were taken at 0,24 and $48 \mathrm{~h}$. The wound area was measured by ImageJ software (NIH, Bethesda, MD, USA), more than five random fields were selected, and the mean value per field was calculated.

\section{Cell invasion assay}

As previously described, ${ }^{25} \mathrm{MCF}-7$ cells were trypsinized and resuspended in culture medium containing $2 \%$ FBS. A total $1 \times 10^{5}$ cells that were pretreated with RS102895, U0126, LiCl or LY294002 were seeded into the Matrigel (BD Biosciences, San Diego, CA, USA)-coated transwell upper chambers (pore size of $8.0 \mu \mathrm{m}$ ), and medium containing $10 \%$ FBS was added to the lower chamber. After $36 \mathrm{~h}$ of incubation, the cells on the upper surface of the transwell were wiped away with cotton swabs, and the invaded cells on the other side of the transwell were fixed with $4 \%$ formaldehyde and stained with crystal violet. The transmigrated cells were counted in three random microscopic fields.

\section{Western blot analysis}

Cells were lysed with RIPA Lysis Buffer (Beyotime, Jiangsu, China). Protein concentrations were assessed using a DC Protein Assay (Bio-Rad, Benicia, CA, USA). Ten micrograms of protein was electrophoresed by $10 \%$ sodium dodecyl sulfate-PAGE and transferred onto polyvinylidene fluoride membranes. After blocking with tris-buffered saline containing 5\% non-fat dry milk and $0.05 \%$ Tween-20 at room temperature for $1 \mathrm{~h}$, the membranes were incubated overnight at $4{ }^{\circ} \mathrm{C}$ with the following primary antibodies: E-cadherin, vimentin, fibronectin, Snail (Santa Cruz Biotech), GSK-3 $\beta$, p44/42 MAPK, Phospho-p44/42 MAPK, ERK, phosphoERK and $\beta$-actin (Santa Cruz Biotech). After being washed to remove any non-bound primary antibodies, the membranes were then incubated with corresponding secondary antibodies at $37^{\circ} \mathrm{C}$ for $1 \mathrm{~h}$. The immunoreactive bands were developed using Immobilon Western Chemiluminescent HRP Substrate (Millipore, Billerica, MA, USA), and the results were analyzed using Quantity One software (Bio-Rad).

\section{Immunofluorescence}

After treatment with various reagents, MCF-7 cells were fixed with $4 \%$ formaldehyde for $15 \mathrm{~min}$ at $25^{\circ} \mathrm{C}$, permeabilized with $0.4 \%$ Triton X-100 for $15 \mathrm{~min}$ and then blocked with $1 \%$ bovine serum albumin (Sigma) for $1 \mathrm{~h}$. The fixed cells were incubated overnight at $4{ }^{\circ} \mathrm{C}$ with primary antibodies at 1:50 dilutions, washed three times with PBS and incubated with secondary antibodies for $1 \mathrm{~h}$ at $37^{\circ} \mathrm{C}$. The cells were counter-stained with $4^{\prime}, 6$-Diamidine- $2^{\prime}-$ phenylindole dihydrochloride (DAPI). Images were captured with a Nikon eclipse E600 microscope.

\section{Cell elliptical factor assay}

The elliptical factor (EF), which is defined as the ratio of length axis to breadth axis of a cell, was calculated to quantify the morphological changes of MCF-7 cells. ${ }^{26}$ After treatment with MCP-1 or RS102895, images of MCF-7 cells were acquired. The $\mathrm{EF}$ values of the cells were then analyzed using ImageJ software (NIH). The cells with an EF $>2$ were considered to exhibit a polarized morphology.

\section{Phalloidin staining}

Phalloidin was used to label F-actin to indicate cytoskeletal changes as previously described. ${ }^{27}$ After treatment with MCP-1 or RS102895, the cells were fixed and stained with $5 \mu \mathrm{g} / \mathrm{ml}$ of a fluorescent phalloidin conjugate solution (Sigma) for $40 \mathrm{~min}$ at $37^{\circ} \mathrm{C}$. The unbound phalloidin was then removed with PBS. 
Photos were acquired using a confocal laser scanning microscope (Nikon A1, Tokyo, Japan).

\section{Real-time PCR}

After various treatments, total cellular RNA was extracted using a RNAiso Plus kit (Takara, Shiga, Japan) and reverse transcribed using a PrimeScript RT reagent kit (Takara). Cellular gene expression levels were analyzed using a SYBR Premix Ex Taq II kit (Takara) on a CFX96 Touch Real-Time PCR Detection System (Bio-Rad). The cycling conditions were $95^{\circ} \mathrm{C}$ for $30 \mathrm{~s}$ followed by 40 cycles of $95^{\circ} \mathrm{C}$ for $5 \mathrm{~s}$ and $60^{\circ} \mathrm{C}$ for $20 \mathrm{~s}$. Gene expression was normalized to $\beta$-actin levels and calculated using the $2-\Delta \Delta \mathrm{Ct}$ method. The data are presented as fold-changes. The following sets of primers were used in the PCR amplifications: $\beta$-actin (forward, 5'-GGCATCCTCACCCTGAAGTA-3'; reverse, 5'-GG GGTGTTGAAGGTCTCAAA-3'), matrix metallopeptidase-2 (MMP-2; forward, 5'-TTGATGGCATCGCTCAGATC-3'; reverse, 5'-TGTCACGTGGCGTCACAGT-3'), MMP-9 (forward, 5'-TGA CAGCGACAAGAAGTGG-3'; reverse, 5' -CAGTGAAGCGGT ACATAGG-3'), and Snail (forward, 5'-TGCCCTCAAGATGCA CATCCGA-3' ${ }^{\prime}$; reverse, $5^{\prime}$-GGGACAGGAGAAGGGCTTCTC-3' ${ }^{\prime}$ ).

\section{Gelatin zymography}

The activities of MMP-2 and MMP-9 (gelatinases) in MCF-7 cells were assessed by gelatin zymography. Cells $\left(8 \times 10^{5}\right.$ per $\left.\mathrm{ml}\right)$ were seeded in sixwell plates and cultured overnight. PBS was used to wash the wells twice to remove remaining FBS. The cells were then treated with MCP-1, RS102895, U0126 or LiCl in FBS-free medium and incubated for $24 \mathrm{~h}$ again. The culture medium was collected and centrifuged at 1500 r.p.m. for $10 \mathrm{~min}$. The supernatants were freeze-dried and subjected to gelatin zymography. The supernatants were resolved on $10 \%$ sodium dodecyl sulfatePAGE polymerized with $0.1 \%$ gelatin. After electrophoresis, the gels were washed twice with $2.5 \%$ Triton X-100 (Sigma) for $40 \mathrm{~min}$ and incubated in a development buffer $(50 \mathrm{mM}$ Tris- $\mathrm{HCl}$, $\mathrm{pH}$ 7.5, $150 \mathrm{mM} \mathrm{NaCl}, 10 \mathrm{mM} \mathrm{CaCl}_{2}$ ) for $42 \mathrm{~h}$ at room temperature. The gels were then stained with $0.25 \%$ Coomassie blue R-250 (Sigma) for $3 \mathrm{~h}$ and destained with $10 \%$ acetic acid in $5 \%$ ethanol until clear zones were evident. The activity of MMP-2 was represented by the clear zones and captured by a gel imaging system. The clear zones were then quantified using ImageJ (NIH).

\section{Statistical analysis}

The data were obtained from three independent experiments, analyzed using SPSS 16.0 software (IBM, Armonk, NY, USA) and expressed as the mean \pm s.e.m. One-way ANOVA was used to compare data among experimental groups, and the differences between groups were further evaluated by the least significant difference test. The data were considered statistically significant at $P<0.05$.

\section{RESULTS AND DISCUSSION}

MCP-1 stimulated the cellular transformation of MCF-7 cells To test whether stimulation with MCP-1 has an effect on the EMT progression of breast cancer cells, we treated MCF-7 cells with MCP-1 (50 ng/ml) or not for 0 to $48 \mathrm{~h}$. MCF-7 cells lost their cell-cell contacts and their typical epithelial cell morphology and began to acquire the elongated and spindle-shaped, mesenchymal phenotype after $24 \mathrm{~h}$ of MCP-1 treatment, whereas the MCF-7 cells in the control group showed no morphological changes (Figure 1a). Because the morphological changes were more obvious after $48 \mathrm{~h}$ of culture with MCP-1, the EMT-related markers were analyzed at $48 \mathrm{~h}$. In the western blot analysis, the protein levels of the mesenchymal markers fibronectin and vimentin were clearly increased in response to MCP-1 stimulation, whereas the levels of the epithelial cell marker E-cadherin were decreased (Figure 1b). The immunofluorescence data further confirmed the notable upregulation of fibronectin and vimentin and downregulation of E-cadherin in the MCP-1treated MCF-7 cells (Figure 1c). These results showed that MCP-1 plays an important role in the promotion of EMT in MCF-7 cells.

MCP-1 enhanced the migration and invasion of MCF-7 cells As MCP-1 regulates tumor progression through the MCP-1/ CCR2 axis, we next explored the contribution of MCP-1/CCR2 signaling by evaluating the cellular response to RS102895, a small-molecule antagonist of CCR2. To determine whether blocking of MCP-1/CCR2 signaling had an effect on the migration and invasion of MCF-7 cells, wound healing and transwell invasion assays were performed. The cells treated with MCP-1 were more migratory, whereas those treated with RS102895 $(20 \mu \mathrm{M})$ displayed limited motility (Figures 2a and b). RS102895 treatment for $24 \mathrm{~h}$ also significantly inhibited MCP-1induced cell invasion (Figures $2 \mathrm{c}$ and $\mathrm{d}$ ).

Importantly, the MCP-1-stimulated spindle-like mesenchymal transformation was also blocked by RS102895 treatment (Figure 3a). The cell morphological changes were further detected by a cell elliptical factor assay. The results showed that both the cell elliptical factor and the number of cells with an elliptical factor $>2$ increased significantly after MCP-1 treatment, whereas treatment with both MCP-1 and RS102895 decreased the cell elliptical factor and the number of cells with an elliptical factor $>2$ (Figures $3 \mathrm{~b}$ and c). Furthermore, cytoskeletal rearrangement and stress fiber formation were detected using TRITC-phalloidin staining. After treatment with MCP-1 for $24 \mathrm{~h}$, the cells were characterized by a typical fibroblast-like phenotype with actin filaments bundled into thick contractile stress fibers. However, the cells treated with both RS102895 and MCP-1 exhibited high levels of cortical actin that were similar to the control cells (Figure 3d). These data demonstrated that MCP-1 triggered the malignant phenotype of MCF-7 cells through the MCP-1/CCR2 axis and promoted cell motility and invasion in vitro.

\section{Snail-mediated EMT changes of MCF-7 cells were mediated by the MEK/ERK and GSK-3 $\beta$ pathways}

The changes in gene expression that lead to the suppression of the epithelial phenotype and the promotion of the mesenchymal phenotype can be driven by transcription factors such as Snail, Twist and the zinc finger E-box-binding protein Zeb. In this study, we detected changes in the messenger RNA (mRNA) and protein levels of Snail, which showed a rapid increase with MCP-1 treatment. Snail expression was significantly increased after $2 \mathrm{~h}$ of treatment with MCP-1, with no apparent changes in mRNA levels (Figure 4a). This might be a result of a critical 

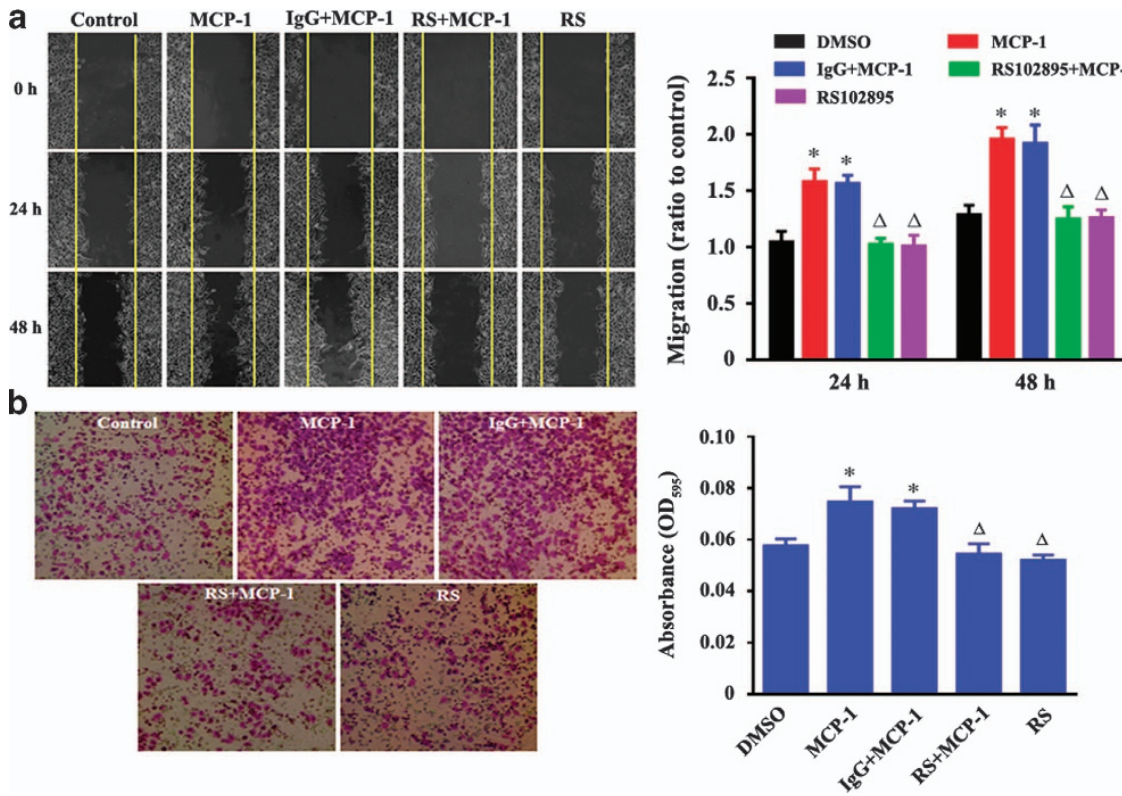

Figure 1 MCP-1 treatment triggers EMT in MCF-7 cells. (a) Cells were treated with MCP-1 (50 ng/ml) or not for 0-48 h, and the morphological alterations of the cells were observed under phase contrast microscopy. (b, c) After MCF-7 cells were treated with MCP-1 for $48 \mathrm{~h}$, the expression levels of FN, vimentin and E-cad were determined by western blotting (b) and immunofluorescence staining (c).

a

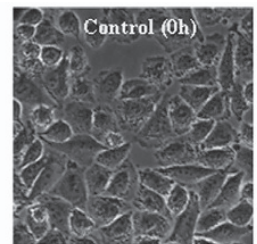

b

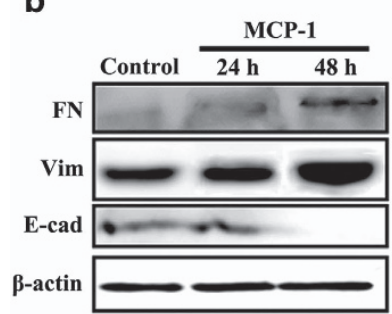

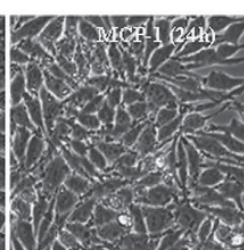
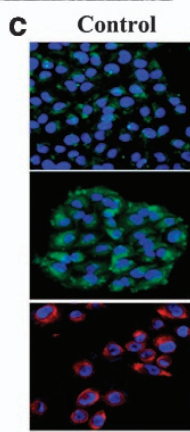

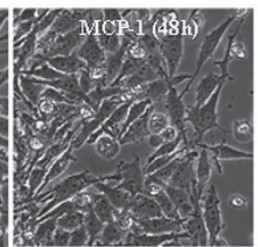

MCP-1

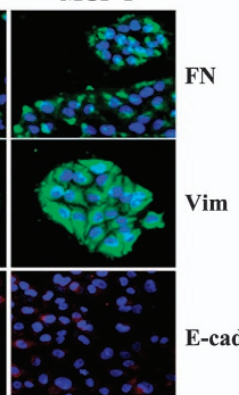

Figure 2 Evaluation of the effect of MCP-1 on the migration and invasion of MCF-7 human breast cancer cells by a wound healing assay. (a) Confluent MCF-7 monolayers were wounded by scraping and treated with MCP-1 $(50 \mathrm{ng} / \mathrm{ml})$. Cell migration to the wound surface was monitored from 0 to $48 \mathrm{~h}$. The relative wound closure was observed under a microscope and photographed (objective 20x). Quantification of the relative closure of the scratch wound (right panel) was determined by calculating the marked area of six randomly selected fields with ImageJ software (NIH). (b) Cell invasion assay was carried out with transwell culture chambers. Cell culture medium containing $50 \mathrm{ng} / \mathrm{ml}$ of MCP-1 was added to the lower wells of the chambers, and MCF-7 cells $\left(2 \times 10^{4}\right)$ were seeded into the upper wells. After $24 \mathrm{~h}$, the cells migrating to the lower surface of the membrane were examined (objective $20 \times$ ). Six different areas of migrated cells were counted for each data point (right panel). All the quantitative data were represented as the mean \pm s.d. $P<0.05$ MCP-1 or IgG+MCP-1 vs DMSO; $P<0.05$ RS (RS102895)+MCP-1 or RS vs MCP-1 or IgG+MCP-1. IgG, immunoglobulin G; MCP-1, monocyte chemoattractant protein-1.

post-translational regulation of MCP-1. After treatment with MCP-1 or RS102895 for $48 \mathrm{~h}$, the nuclear localization of Snail was also assessed by immunofluorescence. A significant upregulation in the nuclear translocation of Snail was observed upon MCP-1 treatment, which was blocked by RS102895 (Figure 4b). These data demonstrate that MCP-1 could not only induce Snail protein expression but also upregulate its nuclear translocation during EMT.

During EMT, numerous pathways such as PI3K/AKT, ERK/ MAPK, p38 MAPK and Jun N-terminal kinase (JNK) may be activated. It is known that a cooperation between the ERK pathway and TGF- $\beta$-induced Smad signaling determines the final cellular response to TGF- $\beta$ during EMT. ${ }^{28}$ Therefore, we determined whether the ERK pathway is involved in MCP-1-mediated EMT in MCF-7 cells. MCP-1 stimulation markedly increased the levels of phospho-ERK in a time-dependent manner (Figure 5a). These results suggested that there was a cross talk between MCP-1 and MAPK/ERK signaling during EMT.

Moreover, Snail can be negatively regulated by GSK- $3 \beta,{ }^{20}$ a downstream target kinase of the PI3K/AKT pathway. GSK-3 $\beta$ maintains its activation in epithelial cells and stimulates the nuclear export and cytoplasmic degradation of Snail. We investigated the phosphorylation levels of GSK-3 $\beta$ after MCP-1 or RS102895 treatment to evaluate whether GSK-3 $\beta$ is involved in the MCP-1-induced activation of Snail. The levels of p-ERK, p-GSK-3 $\beta$ and Snail increased after MCP- 1 treatment for $1 \mathrm{~h}$, and these effects were reversed upon treatment with RS102895 (Figure 5b). RS102895 treatment blocked the upregulation of the mesenchymal markers that were stimulated by MCP-1 and increased the protein level of E-cadherin (Figure 5c). These results indicated that the upregulation of Snail may be due to the activation of ERK signaling and the inhibition of the GSK-3 $\beta$ pathway. 
a

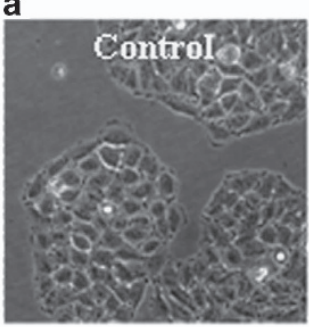

b

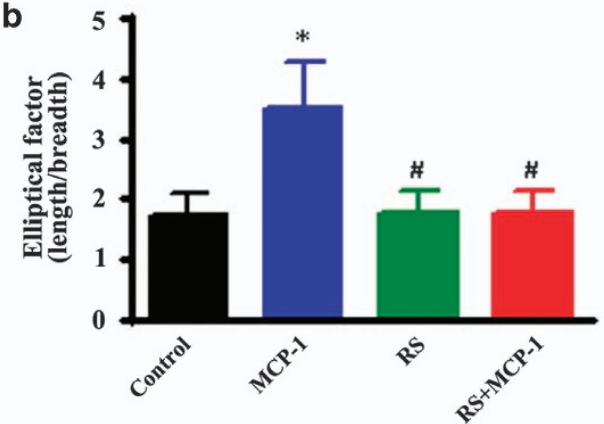

d
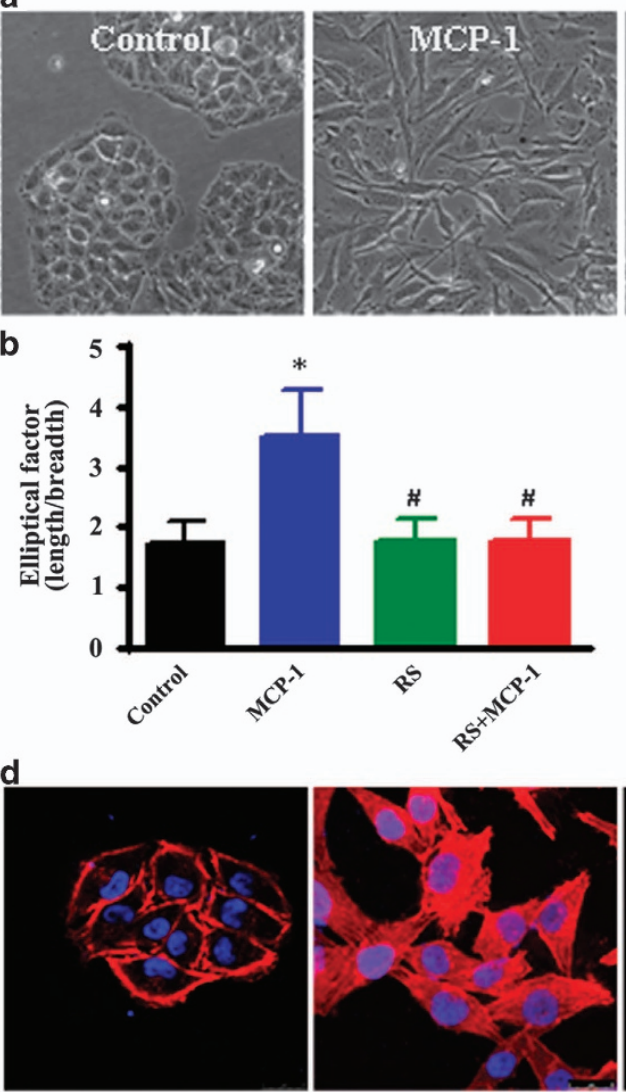
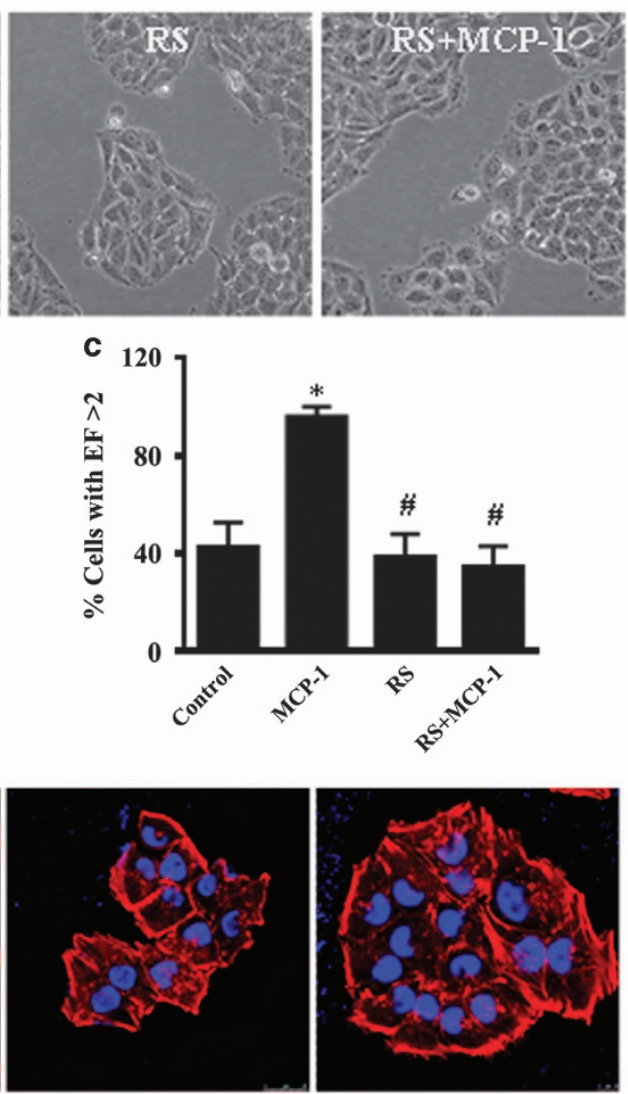

Figure 3 MCP-1 treatment induces a normal polarized phenotype and cytoskeleton rearrangement in MCF-7 cells. (a) Cells were treated with MCP-1 $(50 \mathrm{ng} / \mathrm{ml})$ or pretreated with the MCP-1 competitive inhibitor RS102895 for $48 \mathrm{~h}$, and the polarized morphology was observed under phase contrast microscopy (objective $40 \times$ ). (b) The EF (length/breadth), used as a measure of cell polarization, was calculated for the MCF-7 cells ( $n=38$ for each group). (c) The percentage of cells with an EF $>2$ was calculated for each group. ${ }^{*} P<0.05 \mathrm{MCP}-1$ vs control; ${ }^{\#} P<0.05 \mathrm{RS}$ or RS+MCP-1 vs MCP-1. (d) MCF-7 cells were stained with fluorescent phalloidin to reveal the morphology of the actin cytoskeleton.

\section{ERK/GSK-3ß/Snail signaling mediates the MCP-1-induced EMT of MCF-7 cells}

We further investigated the relationship between the ERK pathway and MCP-1-induced Snail signaling. To assess whether ERK signaling was required for MCP-1-induced EMT, ERK signaling was blocked with the MEK1/2 inhibitor U0126 for $1 \mathrm{~h}$. The activation of the ERK signaling pathway was detected by immunoblotting. It was found that phospho-ERK, phosphoGSK-3 $\beta$ and Snail protein levels increased after $48 \mathrm{~h}$ of MCP-1 treatment; however, these increases were blocked by cotreatment with U0126 (Figure 6a). Similarly, the induction of the mesenchymal markers fibronectin and vimentin and the repression of the epithelial marker E-cadherin by MCP-1 were reversed in response to U0126 treatment (Figure 6b). In addition, to evaluate the cellular phenotype and behaviors after U0126 treatment, cell morphology, migration, and adhesion were investigated. The MCP-1-stimulated spindle-like mesenchymal transformation was blocked with U0126 treatment (Figure 6c). Moreover, the MCP-1-induced cell migratory and invasive abilities were also impeded by U0126 (Figures 6d and e). To further evaluate the role of GSK-3 $\beta$ inactivation on MCP-1induced EMT, MCF-7 cells were pretreated with $\mathrm{LiCl}$, a GSK-3 $\beta$ inhibitor, for $1 \mathrm{~h}$ before being treated with MCP-1, and the levels of p-ERK, p-GSK-3 $\beta$, Snail, and the epithelial or mesenchymal markers were determined. The inhibition of GSK-3 $\beta$ activity stimulated the expression of Snail and mesenchymal markers (fibronectin and vimentin) and repressed expression of the epithelial marker E-cadherin (Figures 7a and b). The mesenchymal morphological changes were stimulated by $\mathrm{MCP}-1$ or $\mathrm{LiCl}$ treatment (Figure 7c). We further explored the EMT phenotype accompanied by increased migration and invasion of MCF-7 cells induced by the inhibition of GSK-3 $\beta$. The results showed that the inhibition of GSK-3 $\beta$ with $\mathrm{LiCl}$ could also promote the migration and invasion of MCF-7 cells (Figures $7 d$ and e).

A previous study showed that activation of the PI3K/Akt signaling pathway could inhibit the GSK-3 $\beta$ kinase in renal cell carcinoma cells. ${ }^{29}$ To further investigate the underlying mechanisms involved in MCP-1-mediated EMT in MCF-7 cells, we tested whether MCP-1 affected the PI3K/Akt and GSK-3 $\beta$ signaling pathways. MCP-1 treatment activated Akt, which was accompanied by the inactivation of GSK-3 $\beta$ by phosphorylation of its serine-9 (Ser9) residue in MCF-7 cells (Figure 8a). To further ascertain whether PI3K/Akt signaling was involved in MCP-1-mediated EMT, we examined the effect of LY294002, a PI3K inhibitor, on the activation of ERK, GSK-3 $\beta$ and Akt. We found that LY294002 pretreatment inhibited the MCP-1-induced phosphorylation of Akt, ERK and GSK-3 $\beta$ and reversed the 
a
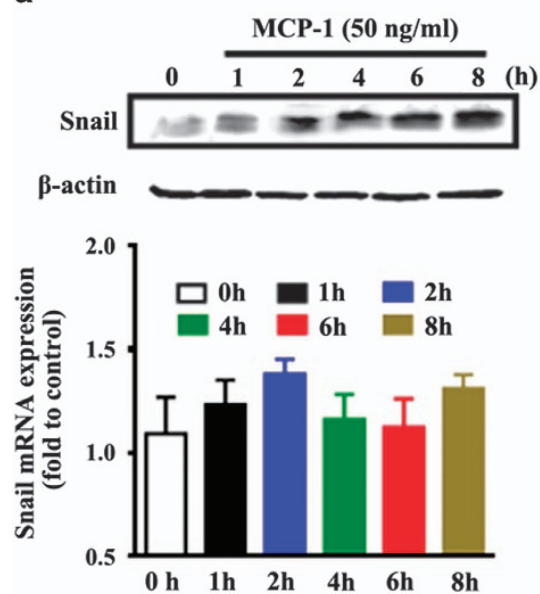

b

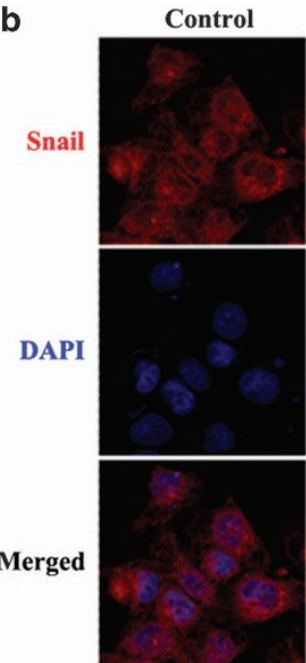

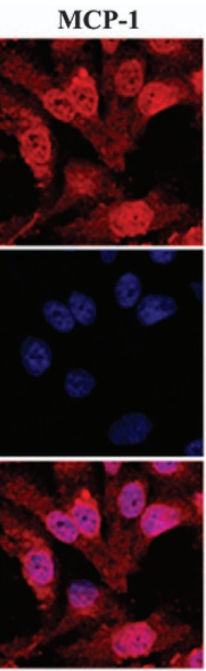

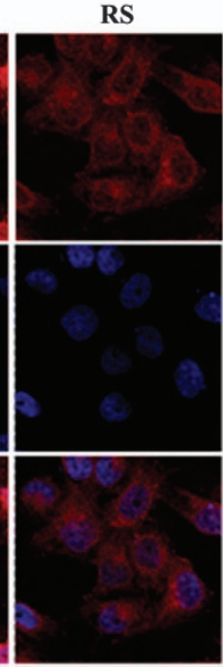

RS+MCP-1

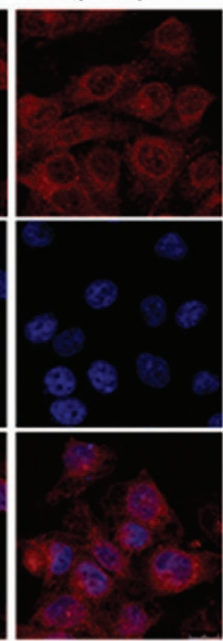

Figure 4 Snail expression and cellular localization induced by MCP-1. (a) Snail expression at both the protein and mRNA levels is upregulated during MCP-1-induced EMT. (b) Cellular localization of Snail in MCF-7 cells. The cells were treated with or without MCP-1 (50 ng/ml) or RS for $48 \mathrm{~h}$, fixed with $4 \%$ paraformaldehyde and processed for indirect immunofluorescence. Snail expression and localization were determined utilizing a Rhodamine-conjugated anti-mouse secondary antibody, and nuclei were stained using DAPI.

spindle-like mesenchymal transformation of MCF-7 cells (Figure 7b). Taken together, these results demonstrated that MCP-1 could induce EMT in MCF-7 cells through the regulation of ERK/GSK-3 $\beta /$ Snail signaling leading to the phosphorylation and inactivation of GSK-3 $\beta$ and the stabilization of Snail.

\section{MCP-1-induced the expression of MMPs and VEGF in MCF-7 cells}

We further assessed the effects of the PI3K/Akt and GSK-3 $\beta$ pathways on MCP-1-mediated MMP-2 and MMP-9 expression and activity in MCF-7 cells. As shown in Figure 9, MCP-1 and $\mathrm{LiCl}$ treatment significantly induced the mRNA transcription and the enzymatic activity of MMP-2. Notably, MCP-1 and $\mathrm{LiCl}$ treatment did not affect MMP-9 mRNA expression. However, the MCP-1 competitive inhibitor RS102895 or the ERK inhibitor U1026 suppressed the MCP-1-induced MMP-2/9 mRNA expression and MMP-2 activity. Moreover, MCP-1 and $\mathrm{LiCl}$ treatments significantly increased the secretion of VEGF, whereas the MCP-1 competitive inhibitor RS102895 and the MEK1/2 inhibitor U0126 both decreased the MCP-1-induced secretion of VEGF (Figure 10).

\section{DISCUSSION}

Chemokines play a critical role in the selective recruitment of monocytes and the G-protein-coupled receptor-induced activation of chemotaxis. ${ }^{30} \mathrm{MCP}-1$ is one of the key chemokines of the $\mathrm{C}-\mathrm{C}$ chemokine family that regulate the migration and infiltration of macrophages. ${ }^{31}$ In the present study, we have shown that the MCP-1-induced EMT of MCF-7 breast carcinoma cells is tightly correlated with accelerated wound healing and enhanced cell migration and invasion. We demonstrated that MCP-1stimulated tumorigenic signaling with repressed expression of E-cadherin and upregulated expression of vimentin and fibronectin. Moreover, MCP-1 treatment inhibited GSK-3 $\beta$ activity through Ser9 phosphorylation mediated by the MEK/ERK pathway in MCF-7 cells. In addition, Snail, a critical transcription factor involved in the initiation and progression of cancer, was also upregulated and showed increased nuclear translocation. These findings revealed that MCP-1-induced EMT and cell migration is mediated by the ERK/GSK-3 $\beta /$ Snail pathway. MMPs play a key role in tumor growth and metastasis by inducing degradation of the extracellular matrix, alterations in cell-cell interactions, migration and angiogenesis. ${ }^{32,33}$ Here, we found that MCP-1-mediated morphological changes were accompanied by the upregulation and increased activity of MMP-2 and the secretion of VEGF in breast carcinoma cells. These data suggest a role for $\mathrm{MCP}-1$ in regulating the malignant phenotype of breast cancer cells and indicate that MCP-1-induced EMT is a critical mechanism driving the malignancy of breast carcinoma.

EMT is characterized by the loss of epithelial characteristics and the acquisition of a mesenchymal phenotype including increased migratory and invasive properties. In general, the rebuilding of the actin cytoskeleton is a prerequisite for cancer cell motility and invasion. ${ }^{34}$ To sustain dynamic cell elongation and directional motility, cells that undergo EMT are characterized by rearrangements in their actin cytoskeleton and the development of actin-rich membrane projections called lamellipodia, filopodia and invadopodia, which facilitate cell motility and invasion. Finally, cells undergoing EMT acquire increases in cell contractility and levels of actin stress fibers. In our study, these dynamic changes in actin rebuilding were also observed. In MCP-1-induced mesenchymal-like MCF-7 cells, actin filaments were bundled into thick stress fibers throughout the entire cell. Conversely, actin filaments were organized into cortical bundles on the surfaces of tumor cells of epithelial origins. Although cytoskeleton rearrangement is one of the mechanisms contributing to MCP-1-induced EMT, the molecular mechanisms of the dynamic control of F-actin during MCP-1-induced EMT remain to be elucidated.

The downregulation of E-cadherin is regarded as one of the critical molecular features involved in the loss of cell-cell adhesion driving cancer invasion and metastasis. ${ }^{35} \mathrm{~A}$ decrease 
a

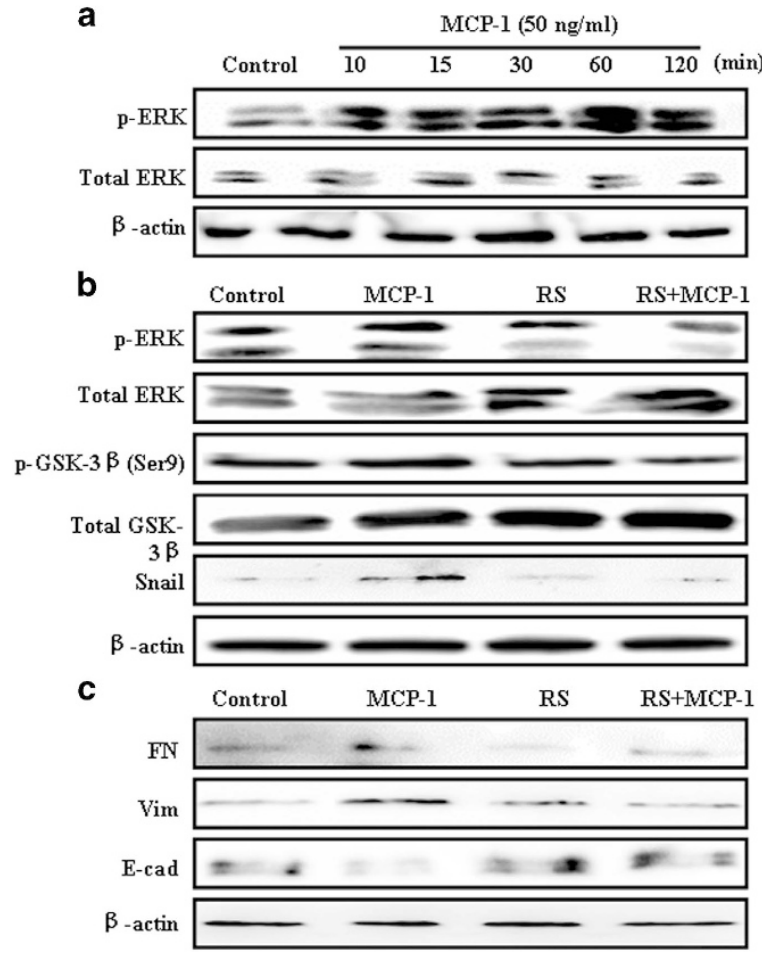

Figure 5 MCP-1 treatment enhances ERK and GSK-3 $\beta$ (Ser9) phosphorylation in MCF-7 cells. (a) MCP-1 induces ERK activation in a time-dependent manner. MCF-7 cells were serum-starved overnight and treated with $50 \mathrm{ng} / \mathrm{ml}$ of MCP-1 for the indicated times. Total protein was subjected to western blotting using anti-p-ERK and Akt antibodies. $\beta$-actin was used as a loading control. (b) MCP-1 leads to the inactivation of GSK-3 $\beta$. MCF-7 cells were serum-starved overnight and treated with $50 \mathrm{ng} / \mathrm{ml}$ of MCP-1 or RS for $1 \mathrm{~h}$, and total protein was subjected to immunoblotting with anti-p-ERK, ERK, p-GSK-3 $\beta$, GSK-3 $\beta$ and Snail antibodies. (c) Inhibition of the MCP-1 receptor CCR2 by RS reverses the expression of EMT biomarkers. The expression levels of E-cad, FN, Vim and $\beta$-actin were detected by western blotting. CCR2, cysteine-cysteine chemokine receptor 2; EMT, epithelial-mesenchymal transition; FN, fibrinogen; GSK-3 $\beta$, glycogen synthase kinase-3 $\beta$; MCP-1, monocyte chemoattractant protein-1.

in or a complete loss of E-cadherin expression, mutation, or alternative mechanisms that interfere with the functioning of adherens junctions are observed in carcinoma cells. ${ }^{36-39}$ In our study, a decrease in E-cadherin protein and a cell morphological change from a cobblestone appearance to an elongated spindlelike shape with MCP-1 treatment of MCF-7 cells demonstrated a loss of epithelial cell phenotype. Fibronectin and vimentin are well known as markers of the mesenchymal phenotype. Our data indicated that the protein levels of fibronectin and vimentin were upregulated in MCF-7 cells after MCP-1 treatment, further evidence supporting the hypothesis that MCP-1 induces EMT in breast cancer cells.

Snail, a prominent inducer of EMT, is a highly labile protein and a critical transcriptional regulator of E-cadherin, which can be modulated at both the transcriptional and post-transcriptional levels through a complex signaling network. ${ }^{40}$ Upon binding to E-box sequences in the E-cadherin gene promoter region, Snail recruits various factors that regulate histone modifications, specifically methylation and acetylation at $\mathrm{H} 3 \mathrm{~K} 4, \mathrm{H} 3 \mathrm{~K} 9$ and $\mathrm{H} 3 \mathrm{~K} 27$,
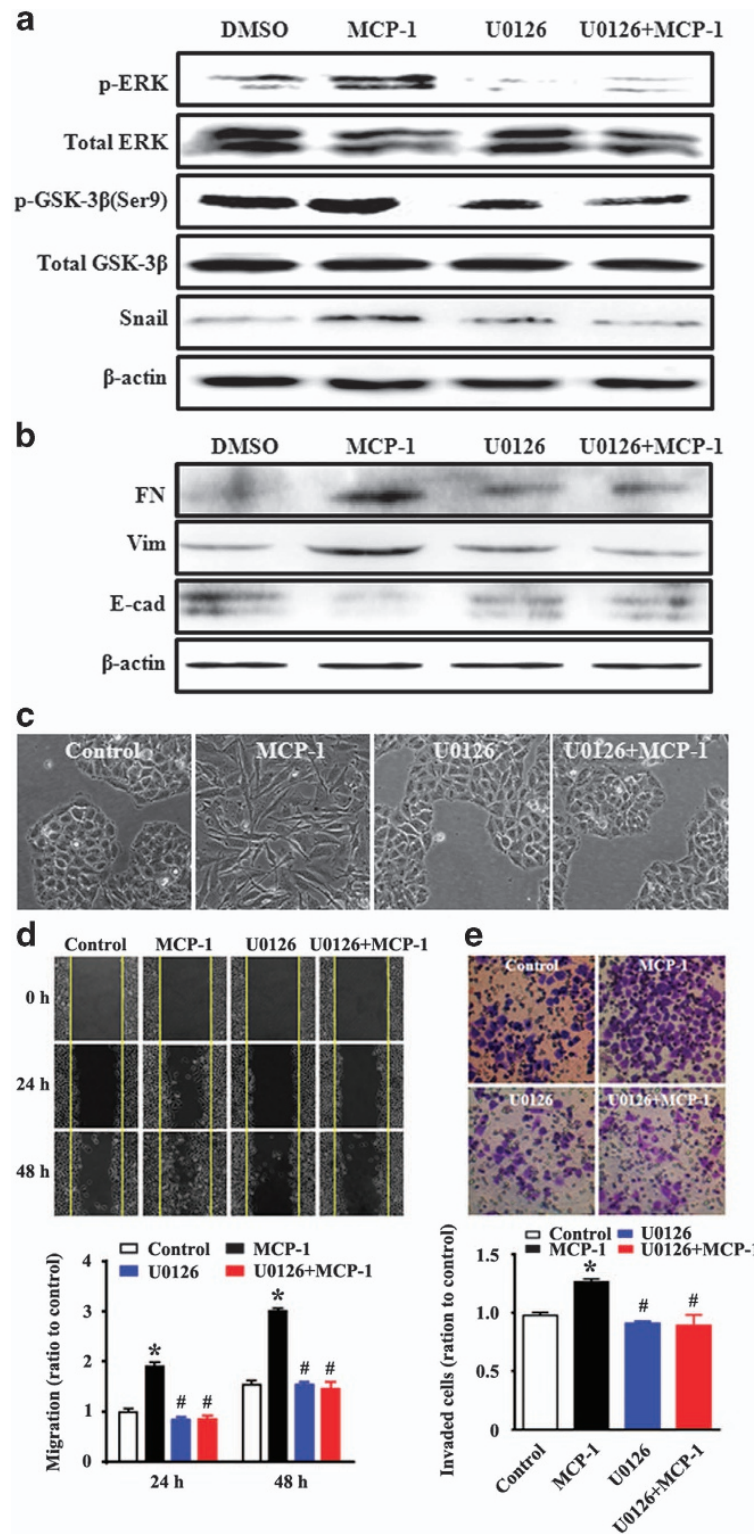

Figure 6 Inhibition of ERK abolishes the MCP-1-induced changes in GSK-3 $\beta$, Snail, EMT biomarker expression, and cell migration and invasion. MCF-7 cells were incubated with or without U0126 for $1 \mathrm{~h}$ before MCP-1 treatment. (a, b) Cell lysates were collected and the protein levels of p-ERK, p-GSK-3 $\beta$ (Ser9), Snail, FN, Vim and E-cad were measured by western blotting. (c) The morphological changes were observed under phase contrast microscopy. (d, e) MCF-7 cells were treated as described above and analyzed for changes in migration by a wound closure assay (d) and a transwell assay (e). ${ }^{*} P<0.05 \mathrm{MCP}-1$ vs control; ${ }^{\#} P<0.05$ U1026

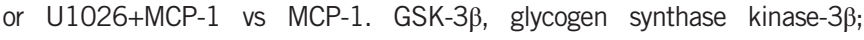
MCP-1, monocyte chemoattractant protein-1.

and eventually represses E-cadherin expression. ${ }^{41-43}$ We observed a significant elevation in the protein level and nuclear translocation of Snail and a concomitant reduction in E-cadherin expression after MCP-1 treatment of MCF-7 cells. In addition to repressing epithelial-related genes, Snail also activated fibronectin, vimentin and MMP-2 expression, contributing to the mesenchymal phenotype. Multiple signaling pathways such as TGF $\beta$-SMAD3, ${ }^{44}$ Wnt- $\beta$-catenin ${ }^{45}$ and Notch $^{46}$ cooperate in the initiation and 

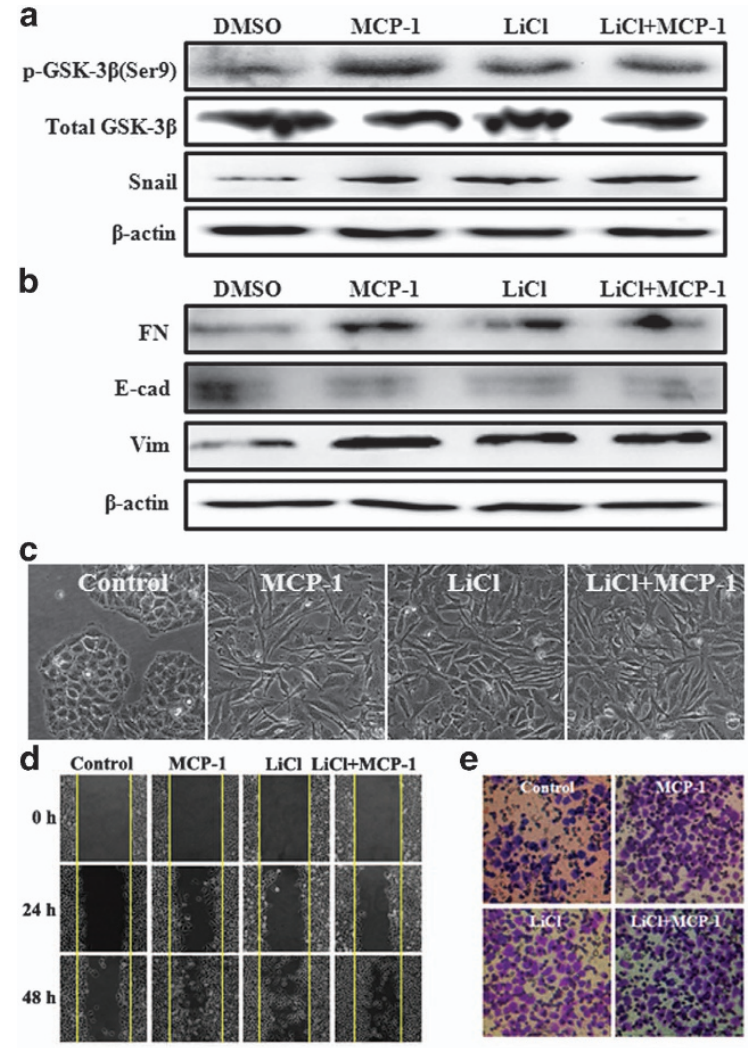

ㅁ Control $=$ MCP-

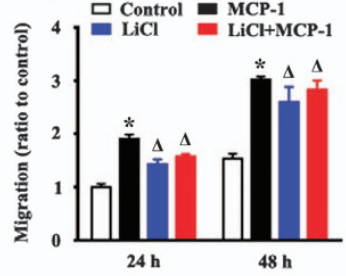

Figure 7 Pretreatment of MCF-7 cells with $\mathrm{LiCl}$ (a GSK-3 $\beta$ inhibitor) abrogates the MCP-1-induced changes in Snail, EMT biomarker expression, and cell migration and invasion. MCF-7 cells were incubated with or without $\mathrm{LiCl}$ for $1 \mathrm{~h}$ before MCP-1 treatment. (a, b) Cell lysates were collected and protein levels of p-GSK-3 $\beta$ (Ser9), Snail, FN, Vim and E-cad were measured by western blotting. (c) The morphological changes were observed under phase contrast microscopy. (d, e) MCF-7 cells were treated as described above and analyzed for changes in migration by a wound closure assay (d) and a transwell assay (e). ${ }^{*} P<0.05$ MCP-1 vs control; ${ }^{\#} P<0.05$ U1026 or U1026+MCP-1 vs MCP-1.

progression of EMT and are known to stimulate Snail expression. ${ }^{47}$ Post-translational modifications are critical regulatory mechanisms that control the localization, degradation and activity of Snail ${ }^{48}$ and Slug. ${ }^{49}$ The glycogen synthase kinase- $3 \beta$ (GSK-3 $\beta$ )-mediated phosphorylation of two Ser-rich motifs inactivates Snail. ${ }^{20}$ The phosphorylation of these two Ser-rich motifs can increase the nuclear export of Snail and label Snail for ubiquitin-mediated degradation. ${ }^{20}$ GSK- $3 \beta$ can be inactivated by phosphorylation of its serine or threonine residue, which can promote Snail stabilization and nuclear translocation and subsequent EMT induction. In the present study, western blot and immunofluorescence analyses showed that MCP-1 treatment enhanced the phosphorylation of GSK-3 $\beta$ (Ser9) and stimulated the nuclear translocation of Snail in MCF-7 cells.
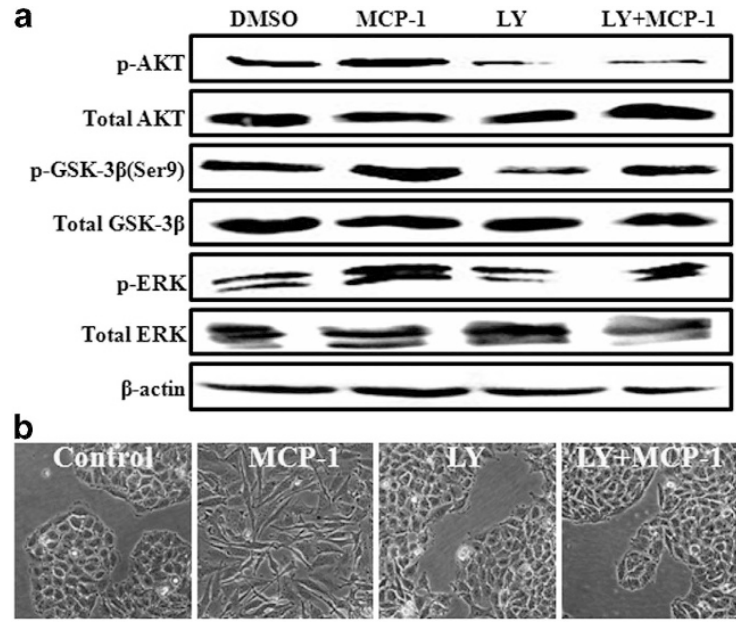

Figure 8 The MCP-1-induced EMT of MCF-7 cells is partially dependent on the PI3K/Akt signaling pathway. (a) The cells were incubated with or without $20 \mathrm{nM}$ LY294002 (LY) for $1 \mathrm{~h}$ before MCP-1 treatment. The

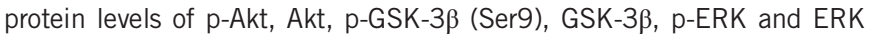
were determined by western blotting. (b) EMT phenotypic changes were observed under phase contrast microscopy. All the data are representative of three independent experiments.

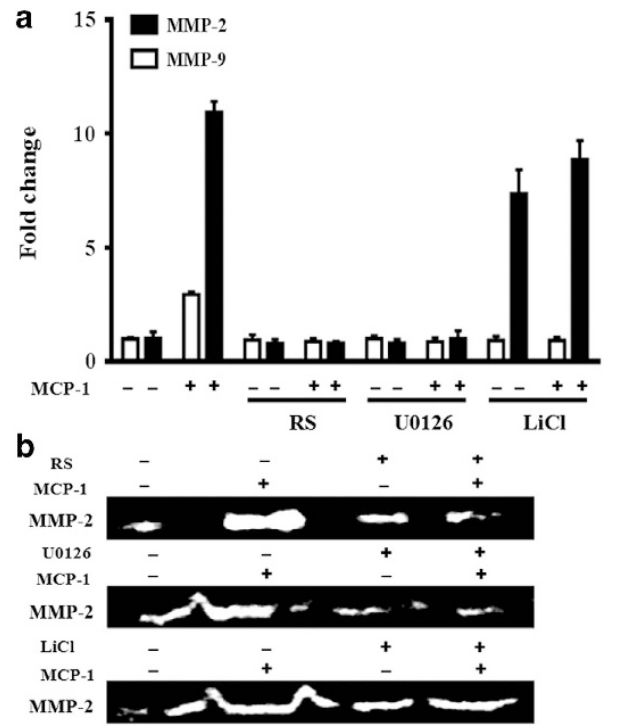

Figure 9 Effects of MCP-1 on MMP-2/9 expression and MMP-2 activity in MCF-7 cells. The cells were incubated with or without the indicated inhibitors (RS, U1026 and LiCl) for $1 \mathrm{~h}$ before MCP-1 treatment. The expression and activity levels of MMP-2/9 were determined by real-time PCR (a) and gelatin zymography (b), respectively.

Various pathways promote Snail activity by regulating GSK-3 $\beta$-mediated phosphorylation. The Wnt and PI3K/Akt pathways inhibit Snail phosphorylation via the inactivation of GSK-3 $\beta .^{50}$ Another report also demonstrated that nuclear factor- $\kappa \mathrm{B}$ signaling could disrupt GSK-3 $\beta /$ Snail interactions. ${ }^{51}$ These signaling pathways are presumed to facilitate the stability of Snail. ERK cascades are key signaling pathways involved in the regulation of multiple cellular processes, such as proliferation, ${ }^{52}$ differentiation, ${ }^{53}$ survival $^{54}$ and transformation. ${ }^{55}$ The aberrant regulation of ERK signaling contributes to cancer and other 


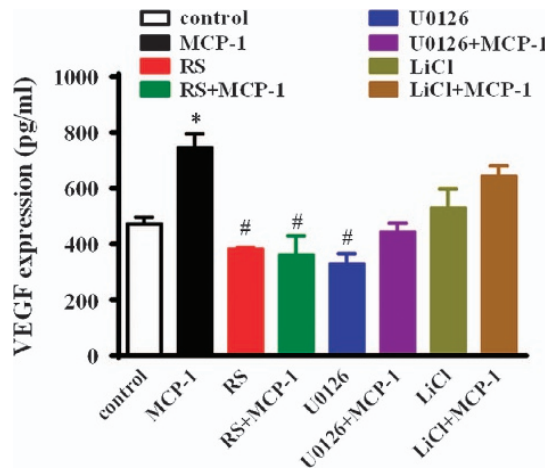

Figure 10 Effects of MCP-1 on VEGF expression in MCF-7 cells. The cells were incubated with or without the indicated inhibitors (RS, $\mathrm{U} 1026$ and $\mathrm{LiCl}$ ) for $1 \mathrm{~h}$ before MCP-1 treatment. The expression of VEGF was determined by ELISA. ${ }^{*} P<0.05 \mathrm{MCP}-1$ vs control; ${ }^{\#} P<0.05$ RS, RS+MCP-1 or U1026 vs control.

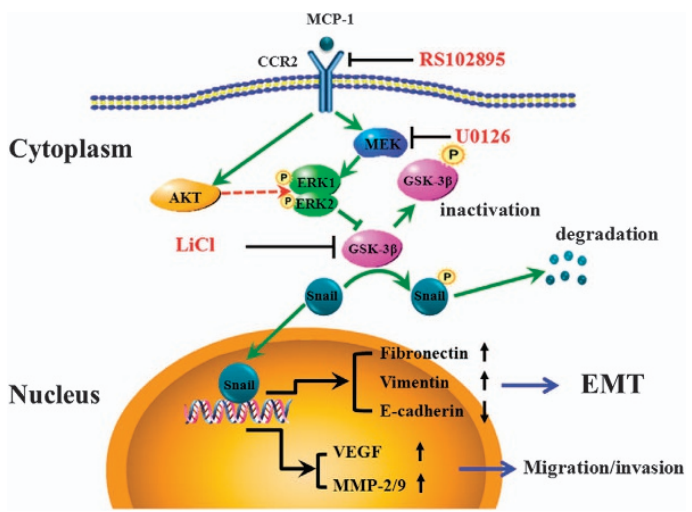

Figure 11 Schematic representation of the proposed mechanism for MCP-1-induced EMT in MCF-7 cells. MCP-1 treatment leads to the activation of the MEK/ERK or PI3K/Akt/ERK signaling pathways. Activated ERK leads to the inactivation of GSK-3 $\beta$ by phosphorylation of the Ser9 active site, which leads to the disassociation of Snail from GSK-3 $\beta$. Snail then translocates to the nucleus where it functions as a transcription factor to regulate FN, Vim and E-cad to initiate EMT or VEGF, MMP-2 and MMP-9 to promote cell migration and invasion.

human diseases. The deregulation of ERK is linked to many types of tumor phenotypes. Gong and colleagues reported that ERK could suppress GSK- $3 \beta$ activation, stimulate $\beta$-catenin signaling and induce cell migration in lipopolysaccharide-treated macrophages. ${ }^{56}$ Additionally, radiation can also lead to the activation of MEK/ERK through the accumulation of reactive oxygen species and the resultant inactivation of GSK-3 $\beta$, eventually leading to Snail nuclear retention and the promotion of mesenchymal phenotypic changes in lung carcinoma epithelial cells. ${ }^{57}$ Although there is no direct evidence that MCP-1 can inactivate GSK-3 $\beta$ via ERK1/2, we hypothesize that MCP-1 can inhibit GSK- $3 \beta$ and activate Snail via the MEK/ERK signaling pathway. To further verify this hypothesis, the cells were pretreated with U0126, a MEK inhibitor. It was found that the MCP-1-induced GSK-3 $\beta$ phosphorylation was abolished by the MEK inhibitor, implying that MEK/ERK signaling is required for the MCP-1-induced inactivation of GSK-3 $\beta$. In addition, the inhibition of GSK-3 $\beta$ by $\mathrm{LiCl}$ significantly promoted the expression of fibronectin, vimentin and Snail and inhibited E-cadherin expression in the MCF-7 cells. However, the inhibition of PI3K/AKT signaling with LY294002 reversed these MCP-1-induced alterations in gene expression. Collectively, our data suggest that ERK/GSK-3 $\beta$ signaling is critical for MCP-1induced EMT in human breast carcinoma MCF-7 cells.

In summary, we demonstrated that MCP-1 could induce EMT of MCF-7 cells. MCP-1 also mediated cell migration and invasion by activating the MEK/ERK pathways and inactivating GSK-3 $\beta$ signaling, leading to increased expression and nuclear retention of Snail (Figure 11). Our findings suggested that MCP-1 might be responsible for the upregulation of Snail by activating ERK signaling and thereby repressing GSK-3 $\beta$. In addition, the MCP-1-induced Snail upregulation might be mediated by a post-transcriptional mechanism. The specific inhibitors RS102895 and U0126 reversed the EMT and decreased the invasiveness of MCF-7 cells by downregulating the expression of MMPs and the secretion of VEGF. These data support the hypotheses that MCP-1 is associated with the acquisition of an aggressive phenotype in breast cancer MCF-7 cells and that inhibiting MCP-1 signaling may be a potential therapeutic strategy for breast cancer.

\section{CONFLICT OF INTEREST}

The authors declare no conflict of interest.

\section{ACKNOWLEDGEMENTS}

This work was supported, in part or in its entirety, by grants from the National Natural Science Foundation of China (11272083, 31470906, 11502049,81471785 and 31470959) and the Sichuan Youth Science and Technology Foundation of China (2014JQ0008).

1 Naruse K, Ueno M, Satoh T, Nomiyama H, Tei H, Takeda M et al. A YAC contig of the human CC chemokine genes clustered on chromosome 17q11.2. Genomics 1996; 34: 236-240.

2 Viedt C, Dechend R, Fei J, Hansch GM, Kreuzer J, Orth SR. MCP-1 induces inflammatory activation of human tubular epithelial cells: involvement of the transcription factors, nuclear factor-kappaB and activating protein-1. J Am Soc Nephrol 2002; 13: 1534-1547.

3 Gillitzer R, Goebeler M. Chemokines in cutaneous wound healing. J Leukoc Biol 2001; 69: 513-521.

4 Goodyear A, Jones A, Troyer R, Bielefeldt-Ohmann H, Dow S. Critical protective role for MCP-1 in pneumonic Burkholderia mallei infection. J Immunol 2010; 184: 1445-1454.

5 Tesch GH, Maifert S, Schwarting A, Rollins BJ, Kelley VR. Monocyte chemoattractant protein 1-dependent leukocytic infiltrates are responsible for autoimmune disease in MRL-Fas(Ipr) mice. J Exp Med 1999; 190: 1813-1824.

6 Fujimoto H, Sangai T, Ishii G, Ikehara A, Nagashima T, Miyazaki M et al. Stromal MCP-1 in mammary tumors induces tumor-associated macrophage infiltration and contributes to tumor progression. Int J Cancer 2009; 125 : $1276-1284$.

7 Ji WT, Chen HR, Lin CH, Lee JW, Lee CC. Monocyte chemotactic protein 1 (MCP-1) modulates pro-survival signaling to promote progression of head and neck squamous cell carcinoma. PLoS One 2014; 9: e88952.

8 Reale M, Intorno R, Tenaglia R, Feliciani C, Barbacane RC, Santoni A et al. Production of MCP-1 and RANTES in bladder cancer patients after bacillus Calmette-Guerin immunotherapy. Cancer Immunol Immunother 2002; 51: 91-98.

9 Lu Y, Chen Q, Corey E, Xie W, Fan J, Mizokami A et al. Activation of MCP-1/ CCR2 axis promotes prostate cancer growth in bone. Clin Exp Metastasis 2009; 26: 161-169.

10 Lee CC, Ho HC, Su YC, Lee MS, Hung SK, Lin CH. MCP1-induced epithelial-mesenchymal transition in head and neck cancer by AKT activation. Anticancer Res 2015; 35: 3299-3306. 
11 Ohta M, Kitadai Y, Tanaka S, Yoshihara M, Yasui W, Mukaida N et al. Monocyte chemoattractant protein-1 expression correlates with macrophage infiltration and tumor vascularity in human gastric carcinomas. Int $\mathrm{J}$ Oncol 2003; 22: 773-778.

12 Valkovic T, Dobrila F, Melato M, Sasso F, Rizzardi C, Jonjic N. Correlation between vascular endothelial growth factor, angiogenesis, and tumorassociated macrophages in invasive ductal breast carcinoma. Virchows Arch 2002; 440: 583-588.

13 Lee SH, Kang HY, Kim KS, Nam BY, Paeng J, Kim S et al. The monocyte chemoattractant protein-1 (MCP-1)/CCR2 system is involved in peritoneal dialysis-related epithelial-mesenchymal transition of peritoneal mesothelial cells. Lab Invest 2012; 92: 1698-1711.

14 Esfandiari F, Fathi A, Gourabi H, Kiani S, Nemati S, Baharvand H. Glycogen synthase kinase-3 inhibition promotes proliferation and neuronal differentiation of human-induced pluripotent stem cell-derived neural progenitors. Stem Cells Dev 2012; 21: 3233-3243.

15 Rodionova E, Conzelmann M, Maraskovsky E, Hess M, Kirsch M, Giese T et al. GSK-3 mediates differentiation and activation of proinflammatory dendritic cells. Blood 2007; 109: 1584-1592.

16 Lapid K, Itkin T, D'Uva G, Ovadya Y, Ludin A, Caglio G et al. GSK3beta regulates physiological migration of stem/progenitor cells via cytoskeletal rearrangement. J Clin Invest 2013; 123: 1705-1717.

17 Gupta C, Kaur J, Tikoo K. Regulation of MDA-MB-231 cell proliferation by GSK-3beta involves epigenetic modifications under high glucose conditions. Exp Cell Res 2014; 324: 75-83.

18 Loberg RD, Vesely E, Brosius FC 3rd. Enhanced glycogen synthase kinase3beta activity mediates hypoxia-induced apoptosis of vascular smooth muscle cells and is prevented by glucose transport and metabolism. $J$ Biol Chem 2002; 277: 41667-41673.

19 Wang $\mathrm{H}$, Wang HS, Zhou BH, Li CL, Zhang F, Wang XF et al. Epithelialmesenchymal transition (EMT) induced by TNF-alpha requires AKT/GSK-3beta-mediated stabilization of snail in colorectal cancer. PLoS One 2013; 8: e56664.

20 Zhou BP, Deng J, Xia W, Xu J, Li YM, Gunduz M et al. Dual regulation of Snail by GSK-3beta-mediated phosphorylation in control of epithelialmesenchymal transition. Nat Cell Biol 2004; 6: 931-940.

21 Medici D, Hay ED, Olsen BR. Snail and Slug promote epithelialmesenchymal transition through beta-catenin-T-cell factor-4-dependent expression of transforming growth factor-beta3. Mol Biol Cell 2008; 19: 4875-4887.

22 Piper DR, Hinz WA, Tallurri CK, Sanguinetti MC, Tristani-Firouzi M. Regional specificity of human ether-a'-go-go-related gene channel activation and inactivation gating. J Biol Chem 2005; 280: 7206-7217.

23 Nagarajan D, Melo T, Deng Z, Almeida C, Zhao W. ERK/GSK3beta/Snail signaling mediates radiation-induced alveolar epithelial-to-mesenchymal transition. Free Radic Biol Med 2012; 52: 983-992.

24 Li L, Zhao F, Lu J, Li T, Yang H, Wu C et al. Notch-1 signaling promotes the malignant features of human breast cancer through NF-kappaB activation. PLoS One 2014; 9: e95912.

25 Zhao F, Li L, Guan L, Yang H, Wu C, Liu Y. Roles for GP Ilb/llla and alphavbeta3 integrins in MDA-MB-231 cell invasion and shear flow-induced cancer cell mechanotransduction. Cancer Lett 2014; 344: 62-73.

26 Grande-Garcia A, Echarri A, de Rooij J, Alderson NB, Waterman-Storer CM, Valdivielso JM et al. Caveolin-1 regulates cell polarization and directional migration through Src kinase and Rho GTPases. J Cell Biol 2007; 177: 683-694.

27 Li S, Zhang J, Yang H, Wu C, Dang X, Liu Y. Copper depletion inhibits $\mathrm{CoCl} 2$-induced aggressive phenotype of MCF-7 cells via downregulation of HIF-1 and inhibition of Snail/Twist-mediated epithelial-mesenchymal transition. Sci Rep 2015; 5: 12410.

28 Gui T, Sun Y, Shimokado A, Muragaki Y. The roles of mitogen-activated protein kinase pathways in TGF-beta-induced epithelial-mesenchymal transition. J Signal Transduct 2012; 2012: 289243.

29 Ho MY, Tang SJ, Chuang MJ, Cha TL, Li JY, Sun GH et al. TNF-alpha induces epithelial-mesenchymal transition of renal cell carcinoma cells via a GSK3beta-dependent mechanism. Mol Cancer Res 2012; 10: 1109-1119.

30 Charo IF, Ransohoff RM. The many roles of chemokines and chemokine receptors in inflammation. N Engl J Med 2006; 354: 610-621.

31 Hoh BL, Hosaka K, Downes DP, Nowicki KW, Fernandez CE, Batich CD et al. Monocyte chemotactic protein-1 promotes inflammatory vascular repair of murine carotid aneurysms via a macrophage inflammatory proteinlalpha and macrophage inflammatory protein-2-dependent pathway. Circulation 2011; 124: 2243-2252.
32 Rundhaug JE. Matrix metalloproteinases, angiogenesis, and cancer: commentary re: AC Lockhart et al, Reduction of wound angiogenesis in patients treated with BMS-275291, a broad spectrum matrix metalloproteinase inhibitor. Clin. Cancer Res., 9: 00-00, 2003. Clin Cancer Res 2003; 9: 551-554.

33 Gialeli C, Theocharis AD, Karamanos NK. Roles of matrix metalloproteinases in cancer progression and their pharmacological targeting. FEBS $J$ 2011; 278: 16-27.

34 Yilmaz M, Christofori G. EMT, the cytoskeleton, and cancer cell invasion. Cancer Metastasis Rev 2009; 28: 15-33.

35 Jeanes A, Gottardi CJ, Yap AS. Cadherins and cancer: how does cadherin dysfunction promote tumor progression? Oncogene 2008; 27: 6920-6929.

36 Frixen UH, Behrens J, Sachs M, Eberle G, Voss B, Warda A et al. E-cadherin-mediated cell-cell adhesion prevents invasiveness of human carcinoma cells. J Cell Biol 1991; 113: 173-185.

37 Pecina-Slaus N. Tumor suppressor gene E-cadherin and its role in normal and malignant cells. Cancer Cell Int 2003; 3: 17.

38 Derksen PW, Liu X, Saridin F, van der Gulden H, Zevenhoven J, Evers B et al. Somatic inactivation of E-cadherin and p53 in mice leads to metastatic lobular mammary carcinoma through induction of anoikis resistance and angiogenesis. Cancer Cell 2006; 10: 437-449.

39 Singhai R, Patil VW, Jaiswal SR, Patil SD, Tayade MB, Patil AV. E-Cadherin as a diagnostic biomarker in breast cancer. N Am J Med Sci 2011; 3: 227-233.

40 Lamouille S, Xu J, Derynck R. Molecular mechanisms of epithelialmesenchymal transition. Nat Rev Mol Cell Biol 2014; 15: 178-196.

41 Gal-Yam EN, Egger G, Iniguez L, Holster H, Einarsson S, Zhang X et al. Frequent switching of Polycomb repressive marks and DNA hypermethylation in the PC3 prostate cancer cell line. Proc Natl Acad Sci USA 2008; 105: 12979-12984.

42 Lin Y, Wu Y, Li J, Dong C, Ye X, Chi YI et al. The SNAG domain of Snail1 functions as a molecular hook for recruiting lysine-specific demethylase 1. EMBO J 2010; 29: 1803-1816.

43 Dong C, Wu Y, Wang Y, Wang C, Kang T, Rychahou PG et al. Interaction with Suv39H1 is critical for Snail-mediated E-cadherin repression in breast cancer. Oncogene 2013; 32: 1351-1362.

44 Heldin $\mathrm{CH}$, Vanlandewijck M, Moustakas A. Regulation of EMT by TGFbeta in cancer. FEBS Lett 2012; 586: 1959-1970.

45 Clevers H, Nusse R. Wnt/beta-catenin signaling and disease. Cell 2012; 149: 1192-1205.

46 Hu YY, Zheng MH, Zhang R, Liang YM, Han H. Notch signaling pathway and cancer metastasis. Adv Exp Med Biol 2012; 727: 186-198.

47 Wang Y, Shi J, Chai K, Ying X, Zhou BP. The role of Snail in EMT and tumorigenesis. Curr Cancer Drug Targets 2013; 13: 963-972.

48 Peinado H, Olmeda D, Cano A. Snail, Zeb and bHLH factors in tumour progression: an alliance against the epithelial phenotype? Nat Rev Cancer 2007; 7: 415-428.

49 Vernon $\mathrm{AE}$, LaBonne $\mathrm{C}$. Slug stability is dynamically regulated during neural crest development by the F-box protein Ppa. Development 2006; 133 : 3359-3370.

50 Yook JI, Li XY, Ota I, Hu C, Kim HS, Kim NH et al. A Wnt-Axin2-GSK3beta cascade regulates Snail 1 activity in breast cancer cells. Nat Cell Biol 2006; 8: 1398-1406.

51 Wu Y, Deng J, Rychahou PG, Qiu S, Evers BM, Zhou BP. Stabilization of snail by NF-kappaB is required for inflammation-induced cell migration and invasion. Cancer Cell 2009; 15: 416-428.

52 Zhang W, Liu HT. MAPK signal pathways in the regulation of cell proliferation in mammalian cells. Cell Res 2002; 12: 9-18.

53 Michailovici I, Harrington HA, Azogui HH, Yahalom-Ronen Y, Plotnikov A, Ching $S$ et al. Nuclear to cytoplasmic shuttling of ERK promotes differentiation of muscle stem/progenitor cells. Development 2014; 141: 2611-2620.

$54 \mathrm{Lu} Z$, Xu S. ERK1/2 MAP kinases in cell survival and apoptosis. IUBMB Life 2006; 58: 621-631.

55 Shojaee S, Caeser R, Buchner M, Park E, Swaminathan S, Hurtz C et al. Erk negative feedback control enables Pre-B cell transformation and represents a therapeutic target in acute lymphoblastic leukemia. Cancer Cell 2015; 28: 114-128.

56 Gong K, Zhou F, Huang H, Gong Y, Zhang L. Suppression of GSK3beta by ERK mediates lipopolysaccharide induced cell migration in macrophage through beta-catenin signaling. Protein Cell 2012; 3: 762-768.

57 Zolotareva TA. [The experimental effect of centimeter-range microwaves on drug biotransformation]. Vopr Kurortol Fizioter Lech Fiz Kult 1990; (3): 50-52. 